\title{
Validation and Verification of Three-dimensional Systems in Laparoscopic Distal Pancreatectomy
}

\author{
EUNSUNG JUN ${ }^{1,2^{*}}$, ABDULWAHAB A. ALSHAHRANI $^{1^{*}}$, KI BYUNG SONG $^{1}$, DAE WOOK HWANG ${ }^{1}$, \\ JAE HOON LEE ${ }^{1}$, SANG HYUN SHIN ${ }^{1}$, YOUNG-JOO LEE ${ }^{1}$ and SONG CHEOL KIM ${ }^{1}$ \\ ${ }^{1}$ Division of Hepato-Biliary and Pancreatic Surgery, Department of Surgery, \\ University of Ulsan College of Medicine, Asan Medical Center, Seoul, Republic of Korea; \\ ${ }^{2}$ Department of Convergence Medicine, Asan Institute for Life Sciences, \\ University of Ulsan College of Medicine and Asan Medical Center, Seoul, Republic of Korea
}

\begin{abstract}
Aim: The three-dimensional (3D) visualization system has been introduced for the technical improvement of laparoscopic surgery, but clinical evidence for its usefulness is lacking. This study aimed to evaluate the usefulness of a $3 D$ system in laparoscopic surgery. Patients and Methods: Between 2015 and 2016, a randomized controlled trial was performed on 61 patients who underwent laparoscopic distal pancreatectomy. The primary outcome was the shortening of operative time. The hospital course, number of technical errors, and clinicians' subjective scores were compared as secondary outcome. Results: There were no significant differences in operative times, hospital course and technical errors. However, depth perception was significantly improved and physical demand was reduced in the $3 D$ group. These advantages became clearer in the later period of the study, with longer operative times, and in spleen-preserving procedures. Conclusion: Subjective scoring through $3 D$ systems was significantly superior, which might lead to better surgical performance in difficult cases.
\end{abstract}

Laparoscopic techniques can minimize surgical wounds, accelerate postoperative recovery, and reduce the duration of hospital stay compared to open techniques $(1,2)$. Previously, laparoscopic surgery depended on two-dimensional (2D) visualization technology, which presented remarkable

\footnotetext{
*These Authors contributed equally to this work.

Correspondence to: Song Cheol Kim, MD, Ph.D., Division of Hepato-Biliary and Pancreatic Surgery, Department of Surgery, University of Ulsan College of Medicine, Asan Medical Center, 88 Olympic-ro 43-gil, Songpa-gu, Seoul 05505, Republic of Korea. Tel: +82 230103936, Fax: +82 260106701, e-mail: drksc@amc.seoul.kr

Key Words: Randomized controlled trial, three-dimensional, laparoscopic surgery, pancreatectomy, depth perception.
}

challenges for those using this technique. These laparoscopic techniques have been further improved by the development of better surgical instruments (3-5). In particular, progression in camera technology has extended the scope of the application of laparoscopic systems, and more detailed surgery has become possible. Nevertheless, the improvement in high-quality cameras has not completely resolved the key limitations of 2D laparoscopy, such as lack of depth perception and visual strain $(6,7)$.

In the 1990s, three-dimensional (3D) visualization technology was proposed to facilitate laparoscopic performance $(8,9)$. In the early stage of 3D system introduction, there was a limitation of image enhancement, and its utilization was also insignificant. However, rapid innovation has provided more advanced 3D technologies that are important for the further development of minimally invasive surgery $(10,11)$.

A report indicated that the technical features and advantages of 3D systems are ineffective and limited (12), but other studies and reviews have suggested that 3D technology improves practical efficiency (13-15). In this study, we focused on laparoscopic distal pancreatectomy (LDP) as a form of laparoscopic abdominal surgery that requires at least $1 \mathrm{~h}$ of operative time. Our aim was to assess the benefits and harms of using the 3D versus the 2D system during LDP and to compare the parameters of imaging quality, adverse effects of surgery, and overall demands of laparoscopic technologies. Through this study, we expect to be able to comprehensively understand the 3D laparoscopic system and provide detailed information on its clinical application.

\section{Patients and Methods}

Study design. This study was performed in compliance with the Declaration of Helsinki. The study protocol was approved by the Institutional Review Board of ASAN Medical Center (IRB No. 20140924) and by the Clinical Research Information Service (registration number: NCT02757690). Written informed consent was obtained 


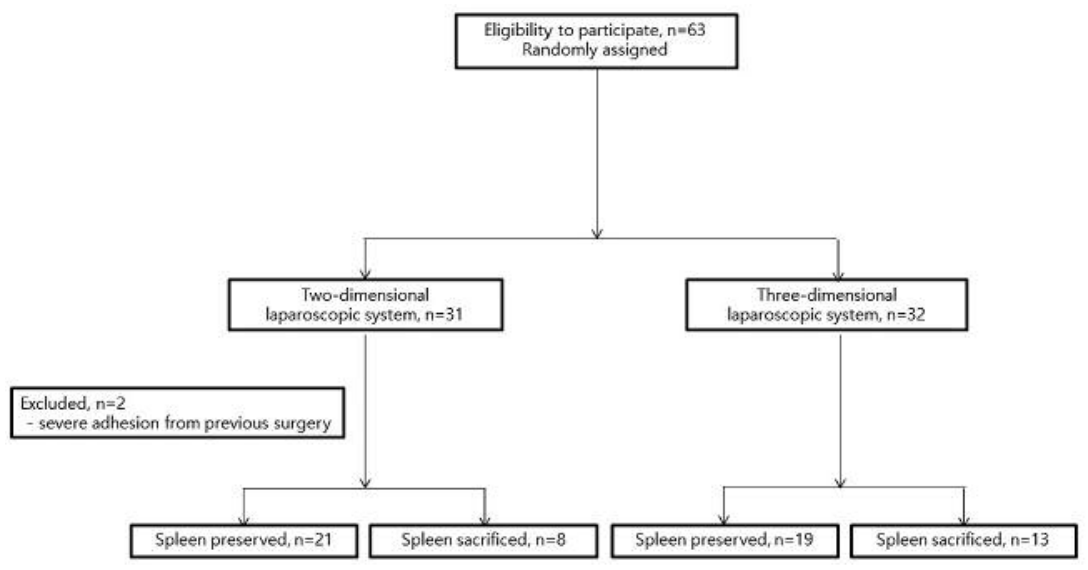

Figure 1. CONSORT diagram for the study.

from all participants. Between 2015 and 2016, patients preoperatively diagnosed with a benign or borderline lesion in the distal pancreas by two radiologists using computed tomography (CT) or magnetic resonance imaging (MRI) were assessed for eligibility. Patients were divided into two groups (3D and 2D) using the block randomization method (16). Two expert surgeons and two first assistants participated. 2D surgery was performed using on Olympus (Seoul, Korea) 2D high definition (HD) laparoscopic system, and 3D surgery was performed using an ENDOEYE FLEX 3D system (LTF-190-10$3 \mathrm{D}$; Olympus). Exclusion criteria were as follows: age $\leq 20$ years or $\geq 80$ years, body mass index (BMI) $>30 \mathrm{~kg} / \mathrm{m}^{2}$, history of severe or recurrent pancreatitis, tumor size in preoperative $\mathrm{CT}$ imaging $>10 \mathrm{~cm}$, history of major abdominal operation, and additional resection for an extra-pancreatic organ. The primary outcome was reduction of the operative time by at least $10 \mathrm{~min}$ through the $3 \mathrm{D}$ system. Operative time was defined as the time from port insertion to wound closure. The secondary outcome was to determine whether use of the 3D system was superior or not inferior to the 2D system for the following factors: Intra-hospital course, short-term outcomes, subjective scoring, and number of technical errors during the operation.

Sample size. Our recent records of surgery were analyzed and showed that the average operation time for LDP was $200 \pm 59 \mathrm{~min}$. The minimum number of patients to verify our hypothesis that the operative time could be reduced by at least $10 \mathrm{~min}$ using the $3 \mathrm{D}$ system was calculated. A sample size of 26 patients for each group was necessary to detect superiority using a one-sided design $(81 \%$ power, two-sample $t$-test). The margin of superiority was -0.167 . The true difference between the means was assumed to be -0.400 . The significance level $(\alpha)$ of the test was 0.02500 . All data were drawn from populations with standard deviations of 0.600 and $0.800(17,18)$.

Data collection. The analysis was divided into three parts: Clinical factors, subjective scoring of clinicians, and technical errors during surgery. The medical records were reviewed to collect their characteristics, hospital stay, time to start eating, recovery of general condition, pathological examination, blood results, and radiological examination parameters. The subjective scoring system was analyzed from the perspective of the operator and first assistant, which depended on three main categories: Image quality (scores of
1-9, bad to good), which included depth perception, sharpness, contrast, and ghosting; adverse effects (scores of 0-5, good to worse), which included visual strain, headache, facial discomfort, ear discomfort, and physical discomfort; and overall demand (scores of 0-5, easy to difficult), which included mental demand, physical demand, and performance success $(12,19)$. Finally, the operation video was analyzed to assess the operative time and the number of technical errors.

Statistical analysis. Statistical analyses were performed using SPSS version 21.0 (IBM, Armonk, NY, USA). Data are expressed as the average \pm standard deviation for continuous variables and as frequency for categorical variables. Student's $t$-tests and chi-square tests were used to analyze differences between the values of continuous and categorical variables, respectively. A $p$-value of less than 0.05 was accepted as statistically significant.

\section{Results}

Study design. A total of 63 consecutive patients were divided into two groups: 31 and 32 patients were assigned to the $2 \mathrm{D}$ and 3D system, respectively. Of the 31 patients in the 2D group, two with a history of abdominal surgery were excluded because of a more severe adhesion than expected (Figure 1). Twenty-one patients in the 2D group underwent a spleen-preserving procedure and eight had a spleensacrificing procedure. In the 3D group, 19 patients underwent a spleen-preserving procedure and 13 had a spleen-sacrificing procedure.

Demographics and short-term outcomes of patients. The patient and tumour characteristics were compared (Table I). There were no significant differences in age, gender, BMI, past history, laboratory results, operator, and pathological diagnosis. In addition, the various clinical features and shortterm outcomes were also analyzed (Table II). There was no 
Table I. Host and tumor characteristics of the study population.

\begin{tabular}{|c|c|c|c|}
\hline Characteristic & $2 \mathrm{D}(\mathrm{n}=29)$ & $3 \mathrm{D}(\mathrm{n}=32)$ & $p$-Value \\
\hline \multicolumn{4}{|l|}{ Age, years } \\
\hline Mean \pm SD & $49.1 \pm 13.7$ & $52.0 \pm 14.1$ & 0.424 \\
\hline \multicolumn{4}{|l|}{ Gender, n } \\
\hline Male/female & $14 / 15$ & $11 / 21$ & 0.270 \\
\hline \multicolumn{4}{|l|}{$\mathrm{BMI}, \mathrm{kg} / \mathrm{m}^{2}$} \\
\hline Mean \pm SD & $23.9 \pm 3.3$ & $24.5 \pm 5.4$ & 0.623 \\
\hline \multicolumn{4}{|l|}{$\begin{array}{l}\text { Previous history of } \\
\text { abdominal surgery, } n\end{array}$} \\
\hline No/yes & $20 / 9$ & $23 / 9$ & 0.804 \\
\hline \multicolumn{4}{|l|}{$\begin{array}{l}\text { Previous history of } \\
\text { pancreatitis, } n\end{array}$} \\
\hline No/yes & $23 / 6$ & $24 / 8$ & 0.689 \\
\hline \multicolumn{4}{|l|}{ Operator, $\mathrm{n}$} \\
\hline Surgeon $1 / 2$ & $22 / 7$ & $21 / 11$ & 0.381 \\
\hline \multicolumn{4}{|l|}{ Tumor location, $\mathrm{n}$} \\
\hline Body/tail & $5 / 24$ & $5 / 27$ & 0.865 \\
\hline \multicolumn{4}{|l|}{ Tumor size, cm } \\
\hline Mean \pm SD & $3.63 \pm 1.68$ & $3.56 \pm 1.92$ & 0.883 \\
\hline \multicolumn{4}{|l|}{ Histological diagnosis, $n$} \\
\hline IPMN & 6 & 12 & 0.445 \\
\hline SPN & 6 & 7 & \\
\hline NET & 4 & 5 & \\
\hline $\mathrm{MCN}$ & 3 & 4 & \\
\hline SCA & 5 & 2 & \\
\hline Other & 5 & 2 & \\
\hline \multicolumn{4}{|l|}{ Laboratory test, mean \pm SD } \\
\hline $\mathrm{WBC}, \times 10^{3} / \mu \mathrm{I}$ & $6.3 \pm 1.6$ & $6.5 \pm 1.8$ & 0.664 \\
\hline $\mathrm{Hb}, \mathrm{g} / \mathrm{dl}$ & $13.2 \pm 1.6$ & $13.1 \pm 1.4$ & 0.755 \\
\hline Platelet count, $\times 10^{3} / \mu \mathrm{I}$ & $224.7 \pm 60.8$ & $237.8 \pm 55.8$ & 0.384 \\
\hline Prothrombin time, $\mathrm{s}$ & $10.1 \pm 3.6$ & $9.3 \pm 4.1$ & 0.387 \\
\hline AST, IU/I & $19.7 \pm 5.7$ & $18.9 \pm 5.8$ & 0.598 \\
\hline ALT, IU/I & $20.3 \pm 11.8$ & $17.5 \pm 8.4$ & 0.274 \\
\hline Total bilirubin, mg/dI & $1.2 \pm 3.4$ & $0.4 \pm 0.2$ & 0.228 \\
\hline Amylase, U/I & $62.3 \pm 18.4$ & $79.6 \pm 66.0$ & 0.179 \\
\hline Lipase, U/I & $41.1 \pm 26.4$ & $49.2 \pm 47.3$ & 0.418 \\
\hline
\end{tabular}

2D: Two-dimensional; 3D: three-dimensional; SD: standard deviation; BMI: body mass index; IPMN: intraductal papillary mucinous neoplasm; SPN: solid pseudopapillary neoplasm; NET: neuroendocrine tumor; MCN: mucinous cystic neoplasm; SCA: serous cystic neoplasm; WBC: white blood cell count; $\mathrm{Hb}$ : hemoglobin; AST: aspartate transaminase; ALT: alanine transaminase.

transfusion during operation, and no significant difference in the ratio of spleen-preserving, inflammation, hemorrhage, recovery pattern, re-operation, and re-admission between the two groups.

Surgical technique and subjective scoring according to visualization system. Differences in the technical aspects were analyzed through a review of the surgical videos, and the subjective scoring of operators (Table III). The operative time, which was the subject of the primary outcome, was similar for both groups. Among the items of technical error, the frequency of missed grasps appeared to decrease slightly in the 3D group, but this was not significant. However, image quality was superior and the mental and physical demands were significantly reduced in the 3D system. Next, the analysis was conducted between the first 10 cases and the later cases. The adverse effects (headache, physical discomfort) and overall demand (mental and physical demand) of the 3D system decreased remarkably in the later period.

Further analysis was conducted to determine whether these factors were affected by the operative time and surgical procedure. Firstly, the operative time was divided into three categories based on cutoffs of $120 \mathrm{~min}$ and $180 \mathrm{~min}$. There were no differences in the average operative time between the $2 \mathrm{D}$ and $3 \mathrm{D}$ groups in the three categories. As the operative time increased, the number of technical errors also increased. The degree of increase was more pronounced for missed grasps, but there were no significant differences between the two groups (Figure 2A). In Figure 2B-D, the comparison of subjective scores by operative time showed that the advantages of the 3D system became clearer with longer operative time.

Secondly, we analyzed the influence of the surgical procedure. Patients were divided into two categories by spleen-preserving procedure (Table IV). The difference between the two groups was clear in the spleen-preserving procedure rather than the spleen-sacrificed procedure. In particular, depth perception, sharpness, and contrast increased relatively and mental and physical demand was relatively reduced in the $3 \mathrm{D}$ system.

Surgical technique and subjective scoring between operator and first assistant. A comparative analysis of the subjective scoring between the operators and first assistants was performed. Except for ear discomfort, there was no difference between the two groups (Table V). The six factors (depth perception, sharpness, contrast, physical discomfort, mental demand, and physical demand) that differed from the subjective scoring analysis between the operators (Table III) were compared with the results of the first assistant. Of these, three factors (depth perception, sharpness, contrast) related to imaging still showed superiority in 3D systems (Table VI).

\section{Discussion}

In 1992, the 3D visualization system was introduced to improve image quality and reduce the learning curve required for surgeons to reach high performance levels (2022). Recently, improved optics has allowed for more accuracy in spatial distance and hand-eye coordination, which lead to increased accuracy in performance and handgrasping $(11,23,24)$. Nevertheless, the application of 3D systems is still limited, and additional research on their scope and utility is required. Most of the previous clinical studies 
Table II. Clinical outcomes after laparoscopic distal pancreatectomy.

\begin{tabular}{|c|c|c|c|}
\hline & $2 \mathrm{D}(\mathrm{n}=29)$ & $3 D(n=32)$ & $p$-Value \\
\hline \multicolumn{4}{|l|}{ Operation } \\
\hline \multicolumn{4}{|l|}{ Transfusion } \\
\hline Absent/present & $29 / 0$ & $32 / 0$ & $>0.99$ \\
\hline \multicolumn{4}{|l|}{ Spleen-preserving } \\
\hline Preserved/sacrificed & $21 / 8$ & $19 / 13$ & 0.284 \\
\hline \multicolumn{4}{|l|}{ Immediately postoperative } \\
\hline $\mathrm{WBC}, \times 10^{3} / \mu \mathrm{I}$ & $13.7 \pm 5.7$ & $11.2 \pm 5.7$ & 0.097 \\
\hline $\mathrm{Hb}, \mathrm{g} / \mathrm{dl}$ & $11.4 \pm 4.2$ & $10.2 \pm 4.6$ & 0.280 \\
\hline Amylase, U/I & $90.2 \pm 47.0$ & $112.9 \pm 126.5$ & 0.366 \\
\hline Lipase, U/I & $99.5 \pm 55.4$ & $87.0 \pm 68.1$ & 0.438 \\
\hline \multicolumn{4}{|l|}{ Postoperative day 1} \\
\hline $\mathrm{WBC}, \times 10^{3} / \mu \mathrm{I}$ & $12.5 \pm 3.4$ & $12.3 \pm 3.5$ & 0.821 \\
\hline $\mathrm{Hb}, \mathrm{g} / \mathrm{dl}$ & $11.9 \pm 2.2$ & $11.9 \pm 1.6$ & 0.949 \\
\hline Platelet count, $\times 10^{3} / \mu \mathrm{I}$ & $201.0 \pm 69.5$ & $211.4 \pm 68.9$ & 0.560 \\
\hline Total bilirubin, mg/dI & $1.0 \pm 0.6$ & $0.8 \pm 0.4$ & 0.104 \\
\hline Amylase, U/I & $161.8 \pm 146.9$ & $172.0 \pm 293.0$ & 0.867 \\
\hline Lipase, U/I & $97.2 \pm 134.7$ & $80.7 \pm 50.4$ & 0.521 \\
\hline \multicolumn{4}{|l|}{ Postoperative day 6 or 7} \\
\hline $\mathrm{WBC}, \times 10^{3} / \mu \mathrm{I}$ & $8.2 \pm 1.8$ & $8.1 \pm 2.8$ & 0.876 \\
\hline $\mathrm{Hb}, \mathrm{g} / \mathrm{dl}$ & $12.6 \pm 1.4$ & $11.9 \pm 1.6$ & 0.081 \\
\hline Platelet count, $\times 10^{3} / \mu \mathrm{I}$ & $311.5 \pm 188.3$ & $313.2 \pm 184.5$ & 0.972 \\
\hline Total bilirubin, mg/dI & $0.5 \pm 0.3$ & $0.4 \pm 0.3$ & 0.319 \\
\hline Amylase, U/I & $78.9 \pm 67.0$ & $72.3 \pm 70.1$ & 0.711 \\
\hline Lipase, U/I & $57.0 \pm 45.6$ & $69.1 \pm 96.4$ & 0.541 \\
\hline \multicolumn{4}{|l|}{ Hospital course } \\
\hline \multicolumn{4}{|c|}{ Time to restarting diet (water), days } \\
\hline Mean \pm SD & $1.2 \pm 0.7$ & $1.1 \pm 0.3$ & 0.543 \\
\hline \multicolumn{4}{|l|}{ Blood transfusion, $\mathrm{n}$} \\
\hline Absent/present & $29 / 0$ & $32 / 0$ & $>0.99$ \\
\hline \multicolumn{4}{|c|}{ Pancreatic fistula (ISGPF grade), $\mathrm{n}$} \\
\hline Grade $\mathrm{A} / \mathrm{B} / \mathrm{C}$ & $27 / 2 / 0$ & $31 / 1 / 0$ & 0.600 \\
\hline \multicolumn{4}{|l|}{ Postoperative ileus, $\mathrm{n}$} \\
\hline Absent/present & $29 / 0$ & $32 / 0$ & $>0.99$ \\
\hline \multicolumn{4}{|l|}{ Wound infection, $\mathrm{n}$} \\
\hline Absent/present & $29 / 0$ & $32 / 0$ & $>0.99$ \\
\hline \multicolumn{4}{|c|}{ Time to removal of drain, days } \\
\hline Mean \pm SD & $4.7 \pm 0.9$ & $4.8 \pm 2.6$ & 0.756 \\
\hline \multicolumn{4}{|c|}{ Length of hospital stay, days } \\
\hline Mean \pm SD & $6.5 \pm 1.0$ & $7.6 \pm 3.5$ & 0.110 \\
\hline \multicolumn{4}{|l|}{ Re-operation, $\mathrm{n}$} \\
\hline Absent/present & $29 / 0$ & $32 / 0$ & $>0.99$ \\
\hline \multicolumn{4}{|l|}{ Re-admission, $\mathrm{n}$} \\
\hline Absent/present & $28 / 1$ & $32 / 0$ & 0.475 \\
\hline
\end{tabular}

ISGPF: International Study Group for Pancreatic Fistula; WBC: white blood cell; Hb: hemoglobin.

were performed on relatively simple operations of less than 1 hour $(12,13,15)$. 3D systems can be useful in relatively more complex and sophisticated operations (25-27). Considering the difficulty of the surgical technique and the operative time, we decided that LDP is a suitable model for confirming the usefulness of the 3D system. By conducting a randomized control study through a well-designed study, we found the following interesting results.

Firstly, an objective result of improvement in technique through the $3 \mathrm{D}$ system was not confirmed. As shown in Table
II, the operative time, which was the parameter and primary outcome of the surgical technique, was not shortened, and there were no significant differences in frequency of technical errors. These findings are consistent with those in published articles $(12,28)$. Considering that the participating surgeons were experts who had already performed more than 100 cases of LDP using the 2D system, it may be difficult to identify a dramatic improvement of their surgical technique.

Secondly, 3D systems exhibit superior image quality, particularly in depth perception, sharpness, and contrast. 
A

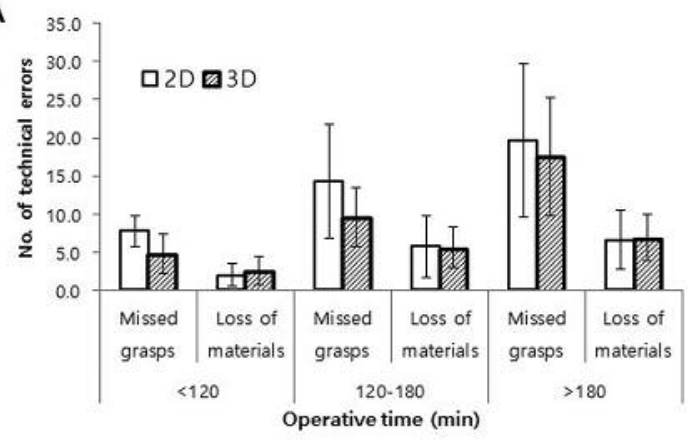

C

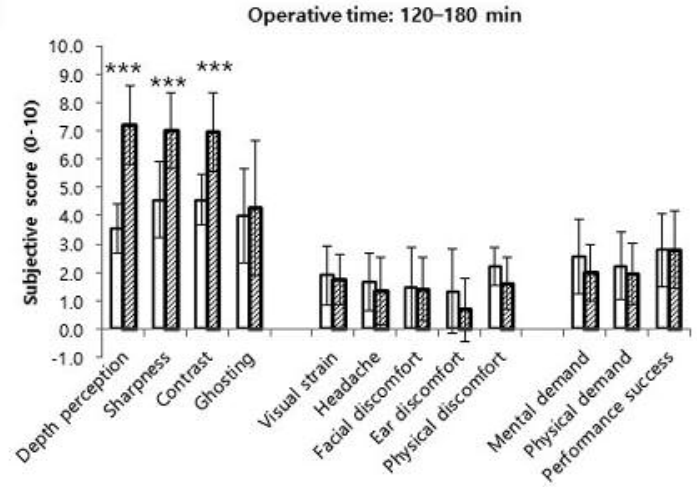

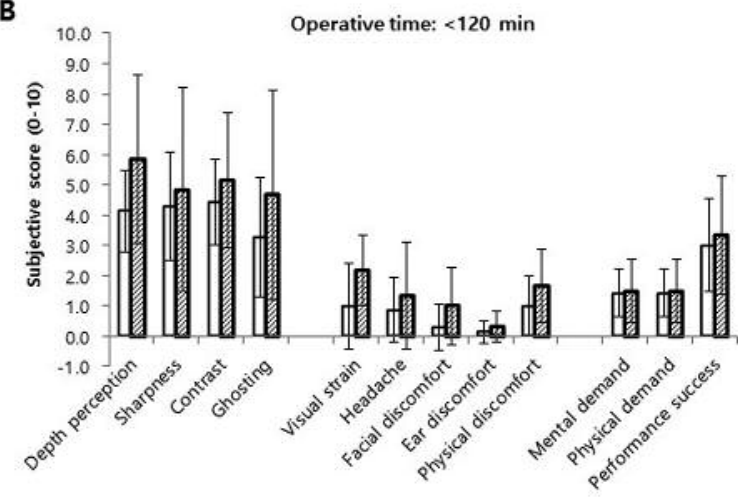

D

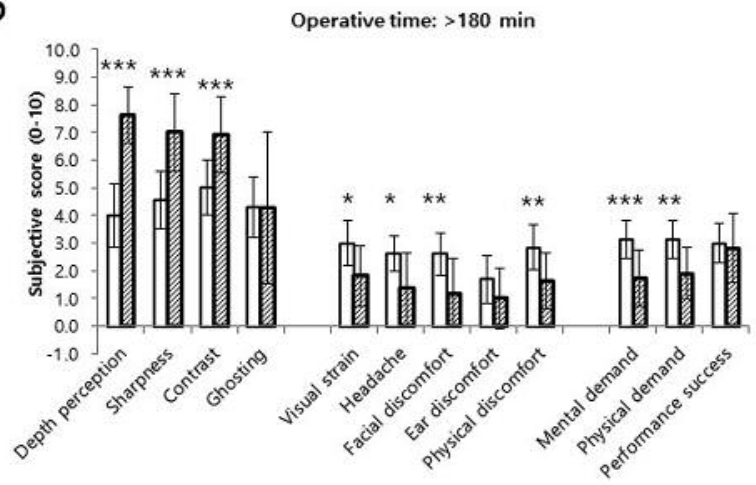

Figure 2. Frequency of technical errors $(A)$ and subjective scoring of laparoscopic distal pancreatectomy according to operative time (B-D) between $2 D$ and $3 D$ groups. Significantly different at $* p<0.01, * * p<0.005$ and $* * * p<0.001$.

Table III. Technical errors and subjective scoring of laparoscopic distal pancreatectomy according to study period and method.

\begin{tabular}{|c|c|c|c|c|c|c|c|c|c|}
\hline & \multicolumn{3}{|c|}{ Total } & \multicolumn{3}{|c|}{ Early period (case no. $\leq 10$ ) } & \multicolumn{3}{|c|}{ Late period (case no. $\geq 11$ ) } \\
\hline & $2 \mathrm{D}(\mathrm{n}=29)$ & $3 \mathrm{D}(\mathrm{n}=32)$ & $p$-Value & $2 \mathrm{D}(\mathrm{n}=10)$ & $3 D(n=10)$ & $p$-Value & $2 \mathrm{D}(\mathrm{n}=19)$ & $3 \mathrm{D}(\mathrm{n}=22)$ & $p$-Value \\
\hline Operative time, $\min$ & $158.7 \pm 43.6$ & $158.2 \pm 41.3$ & 0.968 & $149.6 \pm 36.9$ & $134.4 \pm 39.2$ & 0.384 & $163.4 \pm 47.0$ & $169.0 \pm 38.2$ & 0.675 \\
\hline $\begin{array}{l}\text { Spleen preserved/sacrificed, } \mathrm{n} \\
\text { Subjective scoring, mean } \pm \text { SD } \\
\text { Technical errors }\end{array}$ & $21 / 8$ & $19 / 13$ & 0.284 & $7 / 3$ & $6 / 4$ & 0.639 & $14 / 5$ & $13 / 9$ & 0.326 \\
\hline Missed grasps & $15.4 \pm 9.2$ & $11.8 \pm 7.3$ & 0.114 & $15.6 \pm 10.0$ & $6.6 \pm 3.8$ & 0.029 & $15.3 \pm 8.9$ & $13.8 \pm 7.3$ & 0.585 \\
\hline Loss of materials & $5.4 \pm 3.9$ & $5.6 \pm 3.0$ & 0.824 & $4.3 \pm 4.1$ & $4.1 \pm 2.4$ & 0.916 & $6.1 \pm 3.7$ & $6.1 \pm 3.1$ & $>0.99$ \\
\hline \multicolumn{10}{|l|}{ For imaging quality } \\
\hline Depth perception & $3.9 \pm 1.1$ & $7.1 \pm 1.7$ & $<0.001$ & $3.7 \pm 1.3$ & $6.9 \pm 2.2$ & 0.001 & $4.0 \pm 1.1$ & $7.2 \pm 1.5$ & $<0.001$ \\
\hline Sharpness & $4.5 \pm 1.3$ & $6.6 \pm 2.0$ & $<0.001$ & $4.1 \pm 1.2$ & $5.9 \pm 3.0$ & 0.098 & $4.7 \pm 1.3$ & $6.9 \pm 1.3$ & $<0.001$ \\
\hline Contrast & $4.7 \pm 1.1$ & $6.6 \pm 1.7$ & $<0.001$ & $4.5 \pm 1.1$ & $6.1 \pm 2.4$ & 0.073 & $4.8 \pm 1.1$ & $6.8 \pm 1.2$ & $<0.001$ \\
\hline Ghosting & $4.0 \pm 1.5$ & $4.3 \pm 2.6$ & 0.501 & $4.6 \pm 1.2$ & $6.1 \pm 2.8$ & 0.132 & $3.6 \pm 1.6$ & $3.5 \pm 2.2$ & 0.888 \\
\hline \multicolumn{10}{|l|}{ For adverse effects } \\
\hline Visual strain & $2.2 \pm 1.3$ & $1.8 \pm 1.0$ & 0.270 & $1.9 \pm 1.4$ & $2.0 \pm 1.2$ & 0.862 & $2.3 \pm 1.3$ & $1.8 \pm 0.9$ & 0.126 \\
\hline Headache & $1.9 \pm 1.1$ & $1.3 \pm 1.3$ & 0.079 & $1.7 \pm 0.9$ & $2.0 \pm 1.2$ & 0.534 & $2.0 \pm 1.2$ & $1.0 \pm 1.3$ & 0.018 \\
\hline Facial discomfort & $1.7 \pm 1.4$ & $1.3 \pm 1.2$ & 0.180 & $1.5 \pm 1.4$ & $1.6 \pm 1.0$ & 0.851 & $1.8 \pm 1.4$ & $1.1 \pm 1.2$ & 0.097 \\
\hline Ear discomfort & $1.2 \pm 1.2$ & $0.7 \pm 1.0$ & 0.088 & $1.1 \pm 1.4$ & $0.6 \pm 1.0$ & 0.358 & $1.3 \pm 1.1$ & $0.8 \pm 1.1$ & 0.155 \\
\hline Physical discomfort & $2.2 \pm 1.1$ & $1.6 \pm 1.0$ & 0.031 & $1.8 \pm 1.0$ & $1.9 \pm 0.9$ & 0.818 & $2.4 \pm 1.1$ & $1.5 \pm 1.0$ & 0.007 \\
\hline \multicolumn{10}{|l|}{ For overall demand } \\
\hline Mental demand & $2.6 \pm 1.2$ & $1.8 \pm 1.0$ & 0.009 & $2.5 \pm 1.4$ & $2.3 \pm 1.2$ & 0.736 & $2.6 \pm 1.0$ & $1.6 \pm 0.9$ & 0.002 \\
\hline Physical demand & $2.4 \pm 1.1$ & $1.8 \pm 1.0$ & 0.031 & $2.1 \pm 1.3$ & $2.1 \pm 1.2$ & $>0.99$ & $2.6 \pm 1.0$ & $1.7 \pm 0.9$ & 0.005 \\
\hline Performance success & $2.9 \pm 1.1$ & $2.9 \pm 1.4$ & 0.940 & $2.8 \pm 1.5$ & $2.3 \pm 1.3$ & 0.438 & $3.0 \pm 0.8$ & $3.2 \pm 1.4$ & 0.629 \\
\hline
\end{tabular}


Table IV. Technical errors and subjective scoring of laparoscopic distal pancreatectomy according to spleen preservation and method.

\begin{tabular}{|c|c|c|c|c|c|c|}
\hline & \multicolumn{3}{|c|}{ Spleen preserved } & \multicolumn{3}{|c|}{ Spleen sacrificed } \\
\hline & $2 \mathrm{D}(\mathrm{n}=21)$ & $3 \mathrm{D}(\mathrm{n}=19)$ & $p$-Value & $2 \mathrm{D}(\mathrm{n}=8)$ & $3 \mathrm{D}(\mathrm{n}=13)$ & $p$-Value \\
\hline Operative time, $\min$ & $157.9 \pm 46.6$ & $163.1 \pm 44.1$ & 0.720 & $160.8 \pm 37.2$ & $151.2 \pm 37.3$ & 0.574 \\
\hline \multicolumn{7}{|l|}{ Subjective scoring, mean \pm SD } \\
\hline \multicolumn{7}{|l|}{ Technical errors } \\
\hline Missed grasps & $16.7 \pm 8.9$ & $12.9 \pm 8.1$ & 0.198 & $11.7 \pm 9.7$ & $9.9 \pm 5.4$ & 0.636 \\
\hline Loss of materials & $5.5 \pm 4.4$ & $5.2 \pm 2.4$ & 0.780 & $5.0 \pm 2.1$ & $6.3 \pm 3.8$ & 0.460 \\
\hline \multicolumn{7}{|l|}{ For imaging quality } \\
\hline Depth perception & $3.7 \pm 1.0$ & $7.1 \pm 2.0$ & $<0.001$ & $4.4 \pm 1.3$ & $7.1 \pm 1.3$ & $<0.001$ \\
\hline Sharpness & $4.3 \pm 1.3$ & $7.1 \pm 1.7$ & $<0.001$ & $5.0 \pm 1.1$ & $5.8 \pm 2.2$ & 0.331 \\
\hline Contrast & $4.6 \pm 1.2$ & $6.8 \pm 1.5$ & $<0.001$ & $5.0 \pm 0.5$ & $6.2 \pm 1.9$ & 0.089 \\
\hline Ghosting & $4.1 \pm 1.4$ & $4.2 \pm 2.5$ & 0.923 & $3.6 \pm 1.8$ & $4.6 \pm 2.9$ & 0.393 \\
\hline \multicolumn{7}{|l|}{ For adverse effects } \\
\hline Visual strain & $2.2 \pm 1.2$ & $1.6 \pm 1.0$ & 0.091 & $2.0 \pm 1.6$ & $2.2 \pm 1.0$ & 0.787 \\
\hline Headache & $2.0 \pm 1.1$ & $1.4 \pm 1.3$ & 0.136 & $1.6 \pm 1.1$ & $1.2 \pm 1.4$ & 0.495 \\
\hline Facial discomfort & $1.8 \pm 1.4$ & $1.2 \pm 1.2$ & 0.120 & $1.4 \pm 1.4$ & $1.4 \pm 1.1$ & 0.986 \\
\hline Ear discomfort & $1.2 \pm 1.3$ & $0.7 \pm 1.0$ & 0.190 & $1.1 \pm 1.4$ & $0.7 \pm 0.9$ & 0.330 \\
\hline Physical discomfort & $2.2 \pm 1.1$ & $1.6 \pm 0.9$ & 0.092 & $2.3 \pm 1.0$ & $1.6 \pm 1.1$ & 0.211 \\
\hline \multicolumn{7}{|l|}{ For overall demand } \\
\hline Mental demand & $2.6 \pm 1.0$ & $1.6 \pm 0.9$ & 0.003 & $2.4 \pm 1.5$ & $2.1 \pm 1.1$ & 0.608 \\
\hline Physical demand & $2.6 \pm 1.0$ & $1.6 \pm 0.9$ & 0.004 & $2.1 \pm 1.4$ & $2.2 \pm 1.1$ & 0.959 \\
\hline Performance success & $3.0 \pm 1.0$ & $2.6 \pm 1.5$ & 0.307 & $2.8 \pm 1.4$ & $3.4 \pm 1.1$ & 0.264 \\
\hline
\end{tabular}

Table V. Subjective scoring (mean $\pm S D$ ) of laparoscopic distal pancreatectomy of the operator and first assistant according to method.

\begin{tabular}{|c|c|c|c|c|c|c|}
\hline & \multicolumn{3}{|c|}{$2 \mathrm{D}(\mathrm{n}=29)$} & \multicolumn{3}{|c|}{$3 \mathrm{D}(\mathrm{n}=32)$} \\
\hline & Operator & First assistant & $p$-Value & Operator & First assistant & $p$-Value \\
\hline \multicolumn{7}{|l|}{ For imaging quality } \\
\hline Depth perception & $3.9 \pm 1.1$ & $4.2 \pm 1.0$ & 0.326 & $7.1 \pm 1.7$ & $6.7 \pm 1.6$ & 0.324 \\
\hline Sharpness & $4.5 \pm 1.3$ & $4.9 \pm 1.3$ & 0.196 & $6.6 \pm 2.0$ & $6.0 \pm .2 .1$ & 0.254 \\
\hline Contrast & $4.7 \pm 1.1$ & $5.0 \pm 1.3$ & 0.370 & $6.6 \pm 1.7$ & $6.0 \pm 1.8$ & 0.204 \\
\hline Ghosting & $4.0 \pm 1.5$ & $4.1 \pm 1.8$ & 0.752 & $4.3 \pm 2.6$ & $5.3 \pm 2.1$ & 0.123 \\
\hline \multicolumn{7}{|l|}{ For adverse effects } \\
\hline Visual strain & $2.2 \pm 1.3$ & $2.1 \pm 1.2$ & 0.752 & $1.8 \pm 1.0$ & $2.2 \pm 1.0$ & 0.131 \\
\hline Headache & $1.9 \pm 1.1$ & $1.8 \pm 1.5$ & 0.841 & $1.3 \pm 1.3$ & $1.7 \pm 1.1$ & 0.248 \\
\hline Facial discomfort & $1.7 \pm 1.4$ & $1.8 \pm 1.4$ & 0.850 & $1.3 \pm 1.2$ & $1.6 \pm 1.1$ & 0.196 \\
\hline Ear discomfort & $1.2 \pm 1.2$ & $1.6 \pm 1.3$ & 0.202 & $0.7 \pm 1.0$ & $1.5 \pm 1.1$ & 0.007 \\
\hline Physical discomfort & $2.2 \pm 1.1$ & $2.1 \pm 1.5$ & 0.762 & $1.6 \pm 1.0$ & $2.0 \pm 1.1$ & 0.156 \\
\hline \multicolumn{7}{|l|}{ For overall demand } \\
\hline Mental demand & $2.6 \pm 1.2$ & $2.3 \pm 1.3$ & 0.386 & $1.8 \pm 1.0$ & $2.2 \pm 1.3$ & 0.158 \\
\hline Physical demand & $2.4 \pm 1.1$ & $2.1 \pm 1.2$ & 0.304 & $1.8 \pm 1.0$ & $2.3 \pm 1.4$ & 0.153 \\
\hline Performance success & $2.9 \pm 1.1$ & $2.6 \pm 0.9$ & 0.253 & $2.9 \pm 1.4$ & $3.1 \pm 1.2$ & 0.514 \\
\hline
\end{tabular}

Consistent with these results, the mental and physical demands on surgeons decreased in the $3 \mathrm{D}$ group, which is supported by a previous study that investigated image quality and overall demand of the 3D system (12). These findings may be explained by the advanced visualization optics that allows for more accuracy in spatial distance perception and hand-eye coordination. The better image quality might relate to optical shuttering glasses, which reduce photo transmission to the retina and lead to a decline in the sensory impact on color vision (29). Interestingly, these advantages became clearer in the later period of the study, with longer operative times, and in more complex surgical procedures. This reflects the feasibility and accessibility of this system, which may reduce the burden on the operator, particularly in 
Table VI. Technical errors and subjective scoring $($ mean $\pm S D)$ of the first assistant in laparoscopic distal pancreatectomy.

\begin{tabular}{lrrr}
\hline & \multicolumn{3}{c}{ First assistant } \\
\cline { 2 - 4 } & $2 \mathrm{D}(\mathrm{n}=29)$ & $3 \mathrm{D}(\mathrm{n}=32)$ & $p$-Value \\
\hline For imaging quality & & & \\
$\quad$ Depth perception & $4.2 \pm 1.0$ & $6.7 \pm 1.6$ & $<0.001$ \\
$\quad$ Sharpness & $4.9 \pm 1.3$ & $6.0 \pm 2.1$ & 0.022 \\
Contrast & $5.0 \pm 1.3$ & $6.0 \pm 1.8$ & 0.014 \\
$\quad$ Ghosting & $4.1 \pm 1.8$ & $5.3 \pm 2.1$ & 0.022 \\
For adverse effects & & & \\
$\quad$ Visual strain & $2.1 \pm 1.2$ & $2.2 \pm 1.0$ & 0.590 \\
Headache & $1.8 \pm 1.5$ & $1.7 \pm 1.1$ & 0.668 \\
Facial discomfort & $1.8 \pm 1.4$ & $1.6 \pm 1.1$ & 0.686 \\
$\quad$ Ear discomfort & $1.6 \pm 1.3$ & $1.5 \pm 1.1$ & 0.625 \\
$\quad$ Physical discomfort & $2.1 \pm 1.5$ & $2.0 \pm 1.1$ & 0.756 \\
For overall demand & & & \\
$\quad$ Mental demand & $2.3 \pm 1.3$ & $2.2 \pm 1.3$ & 0.860 \\
Physical demand & $2.1 \pm 1.2$ & $2.3 \pm 1.4$ & 0.660 \\
$\quad$ Performance success & $2.6 \pm 0.9$ & $3.1 \pm 1.2$ & 0.077 \\
\hline
\end{tabular}

difficult cases. Although these advantages are not directly related to shortening of the operative time, operations will be more effective as the burden on the operator decreases.

Thirdly, the first assistant unlike the operator, experienced no reduction of physical demand through the 3D system. Among the subjective scoring results of the operators, only the imaging quality-related factors showed superiority for the first assistant. As far as we are aware, this study is the first to compare operator and first assistant scoring, these results may be a reflection of a difference in concentration and burden between the two.

This study was the first study to validate the clinical usefulness of the 3D system for LDP with an operative time of at least $1 \mathrm{~h}$. The 3D system did not shorten the operative time nor reduce technical errors. However, superiority of the 3D system was confirmed by subjective scoring such as imaging quality and physical demand, particularly in longer and more complicated procedures. Through extensive research on the 3D system, we hope to find a clearer answer to the clinical usability and scope of the 3D system.

\section{Conflicts of Interest}

No potential conflict of interest relevant to this article was reported.

\section{Authors' Contributions}

Substantial contributions to the conception or design of the work: Eunsung Jun, Abdulwahab A. Alshahrani, Sang Hyun Shin, Dae Wook Hwang, Ki Byung Song, Jae Hoon Lee, Young-Joo Lee, Song Cheol Kim; Acquisition of data: Dae Wook Hwang, Ki Byung Song,
Jae Hoon Lee, Young-Joo Lee; Analysis and interpretation of data: Eunsung Jun, Abdulwahab A. Alshahrani, Sang Hyun Shin, YoungJoo Lee; Statistical Analysis: Sang Hyun Shin, Dae Wook Hwang, Ki Byung Song, Jae Hoon Lee; Drafting of manuscript: Eunsung Jun, Abdulwahab A. Alshahrani, Song Cheol Kim; Critical revision: Eunsung Jun, Abdulwahab A. Alshahrani, Song Cheol Kim; Thereafter, in the final revision of this manuscript, all Authors discussed the interpretation of the data and intellectual contents.

\section{Funding}

This study was supported by a Grant from the Korean Health Technology R\&D Project, Ministry of Health \& Welfare, Republic of Korea (No. HI14C2640) and by a grant (2017-7033) from the Asan Institute for Life Sciences, Asan Medical Center, Seoul, Republic of Korea.

\section{References}

1 Buia A, Stockhausen F and Hanisch E: Laparoscopic surgery: A qualified systematic review. World J Methodol 5(4): 238-254, 2015. PMID: 26713285, DOI: 10.5662/wjm.v5.i4.238.

2 Mizrahi I and Mazeh H: Role of laparoscopy in rectal cancer: A review. World J Gastroenterol 20(17): 4900-4907, 2014. PMID: 24803801, DOI: 10.3748/wjg.v20.i17.4900.

3 Spaner SJ and Warnock GL: A brief history of endoscopy, laparoscopy, and laparoscopic surgery. J Laparoendosc Adv Surg Tech A 7(6): 369-373, 1997. PMID: 9449087, DOI: 10.1089/lap.1997.7.369.

4 Daher R, Chouillard E and Panis Y: New trends in colorectal surgery: Single port and natural orifice techniques. World J Gastroenterol 20(48): 18104-18120, 2014. PMID: 25561780, DOI: $10.3748 /$ wjg.v20.i48.18104.

5 Dhumane PW, Diana M, Leroy J and Marescaux J: Minimally invasive single-site surgery for the digestive system: A technological review. J Minim Access Surg 7(1): 40-51, 2011. PMID: 21197242, DOI: 10.4103/0972-9941.72381.

6 Kong SH, Oh BM, Yoon H, Ahn HS, Lee HJ, Chung SG, Shiraishi N, Kitano S and Yang HK: Comparison of two- and three-dimensional camera systems in laparoscopic performance: A novel 3d system with one camera. Surg Endosc 24(5): 11321143, 2010. PMID: 19911222, DOI: 10.1007/s00464-009-07408.

7 Smith R, Schwab K, Day A, Rockall T, Ballard K, Bailey M and Jourdan I: Effect of passive polarizing three-dimensional displays on surgical performance for experienced laparoscopic surgeons. Br J Surg 101(11): 1453-1459, 2014. PMID: 25131843, DOI: $10.1002 /$ bjs. 9601 .

8 Karatas $\mathrm{OH}$ and Toy E: Three-dimensional imaging techniques: A literature review. Eur J Dent 8(1): 132-140, 2014. PMID: 24966761, DOI: 10.4103/1305-7456.126269.

9 Buchs NC and Morel P: Three-dimensional laparoscopy: A new tool in the surgeon's armamentarium. Surg Technol Int 23: 1922, 2013. PMID: 23700184.

10 Wilhelm D, Reiser S, Kohn N, Witte M, Leiner U, Muhlbach L, Ruschin D, Reiner W and Feussner H: Comparative evaluation of hd $2 \mathrm{~d} / 3 \mathrm{~d}$ laparoscopic monitors and benchmarking to a theoretically ideal 3d pseudodisplay: Even well-experienced laparoscopists perform better with 3d. Surg Endosc 28(8): 23872397, 2014. PMID: 24651895, DOI: 10.1007/s00464-014-3487-9. 
11 Sakata S, Watson MO, Grove PM and Stevenson AR: The conflicting evidence of three-dimensional displays in laparoscopy: A review of systems old and new. Ann Surg 263(2): 234-239, 2016. PMID: 26501704, DOI: 10.1097/SLA. 0000000 000001504 .

12 Hanna GB, Shimi SM and Cuschieri A: Randomised study of influence of two-dimensional versus three-dimensional imaging on performance of laparoscopic cholecystectomy. Lancet 351(9098): 248-251, 1998. PMID: 9457094, DOI: 10.1016/S0140-6736(97)08005-7.

13 Kaufman Y, Sharon A, Klein O, Spiegel D, Auslander R and Lissak A: The three-dimensional "insect eye" laparoscopic imaging system-a prospective randomized study. Gynecol Surg 4(1): 31-34, 2007. DOI: 10.1007/s10397-006-0245-6.

14 Wenzl R, Lehner R, Vry U, Pateisky N, Sevelda P and Husslein $\mathrm{P}$ : Three-dimensional video-endoscopy: Clinical use in gynaecological laparoscopy. Lancet 344(8937): 1621-1622, 1994. PMID: 7983998, DOI: 10.1016/S0140-6736(94)90412-X.

15 Sahu D, Mathew MJ and Reddy PK: 3d laparoscopy - help or hype; initial experience of a tertiary health centre. J Clin Diagn Res 8(7): NC01-03, 2014. PMID: 25177597, DOI: 10.7860/JCDR/2014/8234.4543.

16 Suresh K: An overview of randomization techniques: An unbiased assessment of outcome in clinical research. J Hum Reprod Sci 4(1): 8-11, 2011. PMID: 21772732, DOI: 10.4103/0974-1208.82352.

17 Chow SC, Shao J and Wang H: A note on sample size calculation for mean comparisons based on noncentral $t$ statistics. J Biopharm Stat 12(4): 441-456, 2002. PMID: 12477068 DOI: $10.1081 /$ BIP-120016229.

18 Julious SA: Sample sizes for clinical trials with normal data. Stat Med 23(12): 1921-1986, 2004. PMID: 15195324 DOI: 10.1002/sim. 1783

19 Mohamed R, Raman M, Anderson J, McLaughlin K, Rostom A and Coderre $\mathrm{S}$ : Validation of the national aeronautics and space administration task load index as a tool to evaluate the learning curve for endoscopy training. Can J Gastroenterol Hepatol 28(3): 155-159, 2014. PMID: 24619638.

20 Tevaearai HT, Mueller XM and von Segesser LK: 3-D vision improves performance in a pelvic trainer. Endoscopy 32(6): 464468, 2000. PMID: 10863913, DOI: 10.1055/s-2000-643.

21 Peitgen K, Walz MV, Walz MV, Holtmann G and Eigler FW: A prospective randomized experimental evaluation of threedimensional imaging in laparoscopy. Gastrointest Endosc 44(3): 262-267, 1996. PMID: 8885344, DOI: 10.1016/S0016-5107(96) 70162-1.
22 McDougall EM, Soble JJ, Wolf JS, Jr., Nakada SY, Elashry OM and Clayman RV: Comparison of three-dimensional and twodimensional laparoscopic video systems. J Endourol 10(4): 371374, 1996. PMID: 8872737, DOI: 10.1089/end.1996.10.371.

23 Rassweiler J, Safi KC, Subotic S, Teber D and Frede T: Robotics and telesurgery - an update on their position in laparoscopic radical prostatectomy. Minim Invasive Ther Allied Technol 14(2): 109122, 2005. PMID: 16754625, DOI: 10.1080/13645700510010908.

24 Cicione A, Autorino R, Laguna MP, De Sio M, Micali S, Turna B, Sanchez-Salas R, Quattrone C, Dias E, Mota P, Bianchi G, Damiano R, Rassweiler $\mathrm{J}$ and Lima E: Three-dimensional technology facilitates surgical performance of novice laparoscopy surgeons: A quantitative assessment on a porcine kidney model. Urology 85(6): 1252-1256, 2015. PMID: 26099869, DOI: 10.1016/j.urology.2015.03.009.

25 Baum S, Sillem M, Ney JT, Baum A, Friedrich M, Radosa J, Kramer KM, Gronwald B, Gottschling S, Solomayer EF, Rody A and Joukhadar R: What are the advantages of $3 \mathrm{~d}$ cameras in gynaecological laparoscopy? Geburtshilfe Frauenheilkd 77(1): 45-51, 2017. PMID: 28190888, DOI: 10.1055/s-0042-120845.

26 Kozlov Y, Kovalkov K and Nowogilov V: 3D laparoscopy in neonates and infants. J Laparoendosc Adv Surg Tech A 26(12): 1021-1027, 2016. PMID: 27926352, DOI: 10.1089/ lap.2016.0155.

27 Leon P, Rivellini R, Giudici F, Sciuto A, Pirozzi F and Corcione F: $3 \mathrm{D}$ vision provides shorter operative time and more accurate intraoperative surgical performance in laparoscopic hiatal hernia repair compared with 2D vision. Surg Innov 24(2): 155-161, 2017. PMID: 28118788, DOI: $10.1177 / 1553350616687434$.

28 Sorensen SM, Savran MM, Konge L and Bjerrum F: Threedimensional versus two-dimensional vision in laparoscopy: A systematic review. Surg Endosc 30(1): 11-23, 2016. PMID: 25840896, DOI: 10.1007/s00464-015-4189-7.

29 Gurusamy KS, Sahay S and Davidson BR: Three dimensional versus two dimensional imaging for laparoscopic cholecystectomy. Cochrane Database Syst Rev 1: CD006882, 2011. PMID: 21249683, DOI: 10.1002/14651858. CD006882.pub2. 